\title{
PERANCANGAN SISTEM INFORMASI KELENGKAPAN PENGISIAN RESUME MEDIS RAWAT INAP DI RSUD MEURAXA KOTA BANDA ACEH
}

\author{
Yudhi Yanuar $^{1 *}$, Yuli Yanti ${ }^{2}$ \\ ${ }^{1,2}$ Program Studi Informatika, Politeknik Piksi Ganesha Bandung, Bandung, Indonesia \\ *Email: Yudhiyanuar2010@gmail.com
}

\begin{abstract}
Abstrak
Penelitian ini bertujuan untuk merancang sistem informasi kelengkapan pengisian formulir resume medis pasien rawat inap di RSUD Meuraxa Kota Banda Aceh. Metode penelitian yang digunakan adalah metode penelitian kualitatif dengan pendekatan deskriptif. Metode perangkat lunak yang digunakan yaitu menggunakan metode pengembangan waterfall. Dari hasil penelitian yang dilakukan ditemukan permasalahan sebagai berikut: Sistem pengolahan kelengkapan resume medis yang berjalan kurang efektif, Masih adanya resume medis pasien rawat inap yang belum lengkap, Masih sering terjadi keterlambatan pengembalian rekam medis pasien rawat inap.Maka dari itu, penulis membuat perancangan sistem informasi kelengkapan pengisian formulir resume medis pasien rawat inap menggunakan Unified Modelling Language (UML) sebagai metode perancangan, Hypertext Processor (PHP) sebagai aplikasi program dan MySQL sebagai databasenya. Adapun saran yang diberikan penulis adalah Perlu adanya pengembangan sistem informasi kelengkapan resume medis untuk mempermudah mengolah informasi yang dibutuhkan, Perlu adanya sosialisasi keseluruh petugas tentang keharusan pengisian resume medis, perlu mengingatkan kepada petugas ruangan untuk selalu tepat waktu dalam mengembalikan rekam medis.
\end{abstract}

Kata kunci: Perancangan, Resume medis, PHP, MySQL

\begin{abstract}
This research aimed for the inpatient medical resume information system design completeness at RSUD Meuraxa Kota Banda Aceh. Writer did the research observation at RSUD Meuraxa Kota Banda Aceh. Method research were used qualitative methode with descriptive approach, Development methode used waterfall development method. From result of this research couducted found problems: checking process of medical resume $s$ was not effective so that completeness system of medical resume $s$ did not run properly, there was a the inpatient medical resume was not complete, there was often implementation has been delayed return inpatient medical record. Therefore, the authors make the design of information system medical resume inpatients Unified Modeling Language (UML) as a design method, using Hypertext Processor (PHP)as a program application and MySQL as database. The suggestions from writer is there should have been the development of medical resume information system design completeness to ease process of the required information, having a sosialization to all health officer about filling medical resume s, need to remind to an officer of the room on must of filling medical resumes.
\end{abstract}

Keywords: Design, Medical resumes, PHP, MySQL

\section{PENDAHULUAN}

\subsection{Latar Belakang Penelitian}

Perkembangan dunia kesehatan dewasa ini sudah mengalami kemajuan yang sangat pesat baik di negara maju maupun di negara berkembang, rumah sakit merupakan salah satu unit pelayanan yang bergerak dibidang kesehatan, dengan berkembangnya Ilmu Pengetahuan dan Teknologi (IPTEK) dibidang kesehatan khususnya ilmu kedokteran maka pihak rumah sakit dituntut memberikan pelayanan yang efektif dan efisien menjadi syarat mutlak agar tercapainya pelayanan yang optimal. Untuk mendukung terwujudnya pembangunan kesehatan tersebut diperlukan suatu badan organisasi yang berperan dalam memberikan pelayanan kesehatan yang memadai kepada masyarakat, salah satunya adalah rumah sakit (Suparyanto, 2009:2).

Pada era informasi dan teknologi dewasa ini, masyarakat dapat memilih pelayanan kesehatan sesuai keinginan dan kemampuan yang dimilikinya.Oleh karena itu rumah sakit dituntut untuk dapat 
memberikan pelayananan bermutu dan professional seperti harapan pengguna pelayanan kesehatan.Agar dapat memberikan pelayanan dengan fokus kepada pasien, maka sarana pelayanan kesehatan harus dapat menggunakan data dan menggunakannya untuk memprediksikan pelayanan ke masa depan, hal ini penting karena selama ini banyak sarana pelayanan kesehatan yang hanya menggunakan data melihat masa lalu.

Dalam mencapai pelayanan kesehatan yang optimal di sarana pelayanan kesehatan seperti rumah sakit yang didukung oleh data yang lengkap, salah satunya adalah dengan diadakan pelayanan medis.Rekam medis di rumah sakit memiliki peranan yang sangat penting dalam memberikan suatu pelayanan kesehatan terhadap pasien di rumah sakit, karena unit rekam medis merupakan unit yang mengatur pelayanan pasien beserta data-data medis yang berkaitan dengan pasien.

Unit rekam medis medis mempunyai kegiatan yang sangat beragam tidak terpaku hanya dengan kegiatan pencatatan saja, akan tetapi rekam medis juga merupakan sumber data dan informasi dari awal pasien masuk, diberi tindakan, sampai dengan pasien pulang, semua dicatat dalam rekam medis. Data yang dicatat dalam rekam medis tersebut, diolah untuk dijadikan sebagai laporan baik bagi pihak intern maupun ekstern. Rekam medis merupakan salah satu bagian penting dalam pengambilan keputusan guna pengembangan pelayanan, dasar pengobatan dan terapi, serta berfungsi sebagai perlindungan kepentingan hukum baik bagi pasien, tenaga kesehatan maupun institusi pelayanan.

Berdasarkan Permenkes 269/MENKES/PER/III/2008 pada pasal 4 menyebutkan bahwa ringkasan pulang harus dibuat oleh dokter dan dokter gigi yang melakukan perawatan pasien. Resume medis merupakan segala ringkasan informasi penting menyangkut pasien dan bisa dijadikan sebagai dasar untuk melakukan tindakan yang lebih lanjut. Oleh karena itu, resume medis harus segera dibuat ketika pasien diizinkan pulang dari rumah sakit. Resume medis harus singkat dan hanya menjelaskan informasi penting tentang penyakit, pemeriksaan dan tindakan yang dilakukan pengobatannya. Resume medis harus diisi lengkap karena kelengkapan pengisian resume medis merupakan salah satu indicator dari mutu rekam medis, suatu rekam medis dapat dikatakan mempunyai nilai mutu apabila data-data yang dimuat didalamnya diisi secara akurat dan lengkap.

Berdasarkan pengalaman selama observasi di Instalasi Rekam Medis di RSUD Meuraxa Kota Banda Aceh, Penataan (pemeriksaan kelengkapan) isi berkas rekam medis rawat inap dilakukan di ruang rekam medis oleh petugas assembling. Pada saat melakukan penataan, petugas assembling banyak menemukan ketidaklengkapan pengisian formulir resume medis rawat inap, dikarenakan Standar Operasional Prosedural (SOP) belum dijalankan sebagaimana mestinya, dan tidak adanya kerjasama antara dokter dengan perawat dalam hal pengisian formulir resume medis, terutama resume medis masih diisi dengan manual.

\subsection{Pokok Permasalahan}

Berdasarkan latar belakang diatas maka penelitian ini memiliki pokok permasalahan yang akan dibahas yaitu bagaimana perancangan sistem informasi kelengkapan pengisian formulir resume medis pasien rawat inap dengan menggunakan PHP dan MySQL di RSUD Meuraxa Kota Banda Aceh.

\subsection{Tujuan dan Manfaat Penelitian}

\section{a. Tujuan Penelitian}

1) Mengetahui bagaimana perancangan sistem informasi kelengkapan pengisian formulir resume medis pasien rawat inap dengan menggunakan PHP dan MYSQL di RSUD Meuraxa Kota Banda Aceh.

2) Menganalisis pelaksanaan sistem informasi kelengkapan pengisian formulir resume medis pasien rawat inap di RSUD Meuraxa Kota Banda Aceh.

3) Menganalisis permasalahan atau kendala pada sistem informasi kelengkapan pengisian formulir resume medis pasien rawat inap di RSUD Meuraxa Kota Banda Aceh. 
4) Merancang sistem informasi kelengkapan pengisian formulir resume medis pasien rawat inap secara terkomputerisasi untuk mengatasi permasalahan pada sistem informasi resume medis di RSUD Meuraxa Kota Banda Aceh.

\section{b. Manfaat Penelitian}

1) Penulis

Sebagai bahan untuk pembelajaran dan pengembangan maupun pengimplementasian ilmu pengetahuan yang diperoleh selama dibangku perkuliahan dan mampu menerapkannya dengan baik di lapanganpekerjaan nanti.

2) Akademi

Sebagai penambahan ilmu pengetahuan dan wawasan bagi institusi, referensi pustaka terutama berkaitan dengan keilmuan rekam medis untuk penelitian selanjutnya, seluruh mahasiswa dan masyarakat luas tentang sistem informasi kelengkapan pengisian formulir resume medis.

3) Rumah Sakit

Dapat memberikan masukan sebagai bahan pertimbangan bagi rumah sakit dalam mengembangkan sistem informasi kelengkapan pengisian formulir resume medis di RSUD Meuraxa Kota Banda Aceh.

\section{MATERI DAN METODE}

\subsection{Materi}

\section{a. Konsep Rumah Sakit}

Berdasarkan undang-undang No. 44 Tahun 2009 tentang rumah sakit, yang dimaksudkan dengan rumah sakit adalah institusi pelayanan kesehatan yang menyelenggarakan pelayanan kesehatan perorangan secara paripurna yang menyediakan pelayanan rawat inap, rawat jalan, dan gawat darurat.

b. Rekam Medis

Menurut Peraturan Menteri Kesehatan Republik Indonesia Nomor 269/MENKES/PER/III/2008 Pasal 1: "Rekam Medis adalah berkas yang berisikan catatan dan dokumen tentang identitas pasien, pemeriksaan, pengobatan, tindakan dan pelayanan lain yang telah diberikan kepada pasien".

\section{c. Resume Medis}

Menurut Depkes RI dalam pedoman penyelenggaraan dan Prosedur Rekam Medis Rumah Sakit di Indonesia (2006:72) bahwa resume medis adalah ringkasan kegiatan pelayanan medis yang diberikan oleh tenaga kesehatan khususnya dokter selama masa perawatan hingga pasien keluar baik dalam keadaan hidup maupun meninggal.

\section{d. Kelengkapan Resume Medis}

Menurut Permenkes No 269 Tahun 2008, rekam medis harus dibuat secara tertulis, lengkap dan jelas. Rekam medis yang bermutu salah satunya dapat dilihat dari kelengkapan isi rekam medis. Kelengkapan tersebut ditambahkan dengan autentikasi dari rekam medis seperti nama dokter yang merawat, tanda tangan dan tanggal pembuatan.

\section{e. Konsep Rawat Inap}

Keputusan Menteri Kesehatan Republik Indonesia Nomor 560/MENKES/SK/IV/2003 Pelayanan Rawat Inap adalah pelayanan pasien untuk observasi, diagnosis, pengobatan, rehabilitasi medik dan atau upaya pelayanan kesehatan lainnya dengan menginap di rumah sakit.

\section{f. Konsep Kesehatan Elektronik}

Dokumen Elektronik adalah setiap informasi yang dibuat, diteruskan, dikirimkan, diterima atau disimpan dalam bentuk analog, digital, elektromagnetik, optikal, atau sejenisnya, yang dapat dilihat, ditampilkan, dan/didengar melalui computer atau Sistem Elektronik, termasuk tetapi tidak terbatas pada tulisan, suara, gambar, peta, rancangan, foto atau sejenisnya, huruf, tanda, angka, kode akses, simbol atau perforasi yang memiliki makna atau arti atau dapat dipahami oleh orang yang mampu memahaminya.

\section{g. Konsep Perancangan}


Menurut Azhar (2004:331) "perancangan adalah spesifikasi umum dan terinci dari pemecahan masalah berbasis komputer yang dipilih selama tahap analisis".

\section{h. Pengertian Sistem Dan Sistem Informasi}

Menurut Jogiyanto (2005 : 2), "sistem adalah kumpulan dari elemen-elemen yang berinteraksi untuk mencapai suatu tujuan tertentu. Sistem ini menggambarkan suatu kejadian-kejadian dan kesatuan yang nyata, seperti tempat, benda dan orang-orang yang betul-betul ada dan terjadi".

Menurut Azhar Susanto (2002 : 54), "sistem informasi adalah kumpulan dari sub-sub sistem baik fisik maupun non phisik yang saling berhubungan satu sama lain dan bekerja sama secara harmonis untuk mencapai satu tujuan yaitu mengolah data menjadi informasi yang berguna".

\section{i. Konsep Database Management System (DBMS)}

Database atau basis data adalah kumpulan data yang disimpan secara sistematis di dalam komputer yang dapat diolah atau dimanipulasi menggunakan perangkat lunak (program aplikasi) untuk menghasilkvan informasi.

\section{j. Unified Modeling Language (UML)}

Unified Modeling Language (UML) adalah sebuah "bahasa" yang telah menjadi standar dalam industri untuk visualisasi, merancang dan mendokumentasikan sistem piranti lunak. UML menawarkan sebuah standar untuk merancang model sebuah sistem (Shalahuddin, 2013 : 137). UML mendefinisikan diagram-diagram sebagai berikut:
1) Usecase Diagram
2) Class Diagram
3) Sequence Diagram
4) State Chart Diagram
5) Activity Diagram
6) Collaboration Diagram
7) Component Diagram
8) Deployment Diagram

k. Tool Pembangun Aplikasi
1) $\mathrm{PHP}$
2) MySQL
3) XAMPP
4) PhpMyAdmin

\subsection{Metode}

\section{a. Metodologi Penelitian}

Dalam menyelesaikan penelitian ini penulis menggunakan metode penelitian kualitatif dengan pendekatan deskriptif dengan menggambarkan keadaan yang terjadi di lapangan khususnya mengenai analisa kelengkapan pengisian resume medis pasien rawat inap di RSUD Meuraxa yang kemudian membuat perancangan sistem informasi kelengkapan pengisian resume medis. Menurut Sugiono (2013:14) metode penelitian kualitatif adalah :"Metode penelitian kualitatif adalah metode penelitian yang berlandaskan pada filsafat postpositivme, digunakan untuk meneliti pada kondisi obyek yang alamiah, (sebagai lawannya adalah eksperimen) dimana peneliti adalah instrument kunci, pengambilan sampel sumber data dilakukan secara puirposive dan snowboal, teknik pengumpulan dengan tianggulasi (gabungan), analisis data bersifat induktif/kualitatif, dan hasil penelitian kualitatif lebih menekankan makna daripada generalisasi".

b. Teknik Pengumpulan Data

1) Interview (Wawancara)

Interview atau wawancara adalah suatu bentuk komunikasi verbal yang bertujuan untuk memperoleh informasi. Dalam hal ini penulis mengumpulkan data dengan cara wawancara langsung dengan pihak-pihak berwenang yang menangani masalah tentang penelitian ini. 


\section{2) Observasi}

Observasi adalah mengumpulkan data yang tepat dengan mengamati dan meneliti secara langsung kelapangan untuk memperoleh data yang di inginkan sesuai dengan kebutuhan peneliti, sehingga dapat memberigambaran yang jelas tentang aktivitas diRSUD Meuraxa Kota Bandung.

3) Library Reseach (Studi Kepustakaan)

Library Reseach atau Studi Kepustakaan adalah salah satu teknik pengumpulan data dengan mempelajari buku-buku, dokumen-dokumen, serta catatan-catatan yang mendukung sebagai bahan dalam penulisan laporan.

\section{4) Metode Pengembangan Perangkat Lunak}

Pada proses perancangan perangkat lunak, penulis menggunakan model waterfall, karena sistem yang akan dirancang bukanlah dari pengembangan perangkat lunak yang sudah ada tetapi mengembangkan darisistem secara manual ke sistem perangkat lunak, untuk membantu mengatasi kerumitan dan memerinci apa yang harus dilakukan dalam perancangan perangkat lunak.

\section{HASIL DAN PEMBAHASAN}

Alur perancangan sistem informasi kelengkapan pengisian formulir resume medisini menggunakan Unified Modeling Language (UML), dimana sistem yang dirancang merupakan aliran data yang berorientasi pada objek-objek yang ada.

\section{a. Usecase Diagram}

Usecase diagram disajikan pada gambar 1.

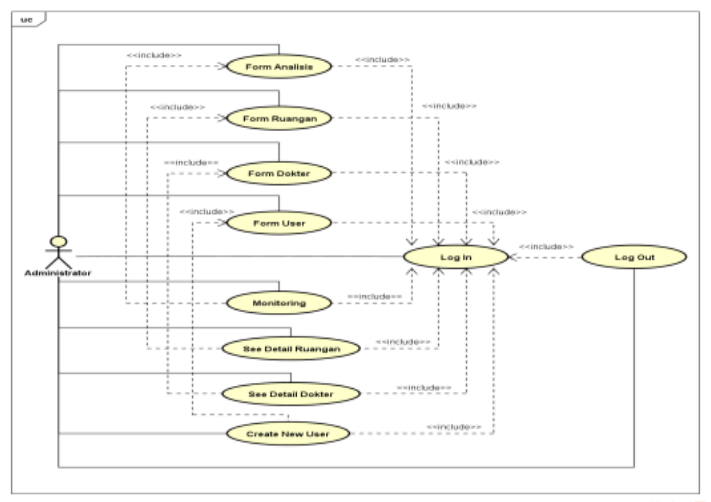

Gambar 1. Usecase Diagram

b. Class Diagram

Class diagram disajikan pada gambar 2.

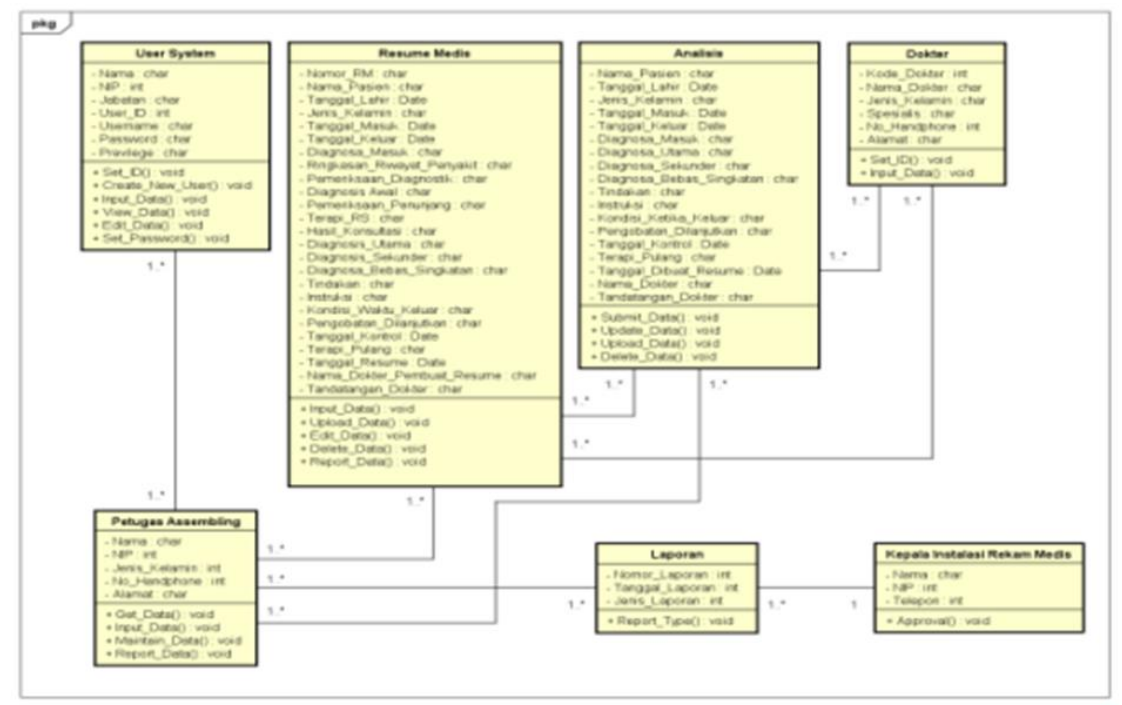

Gambar 2. Class Diagram 
c. Activity Diagram

Activity diagram disajikan pada gambar 3.

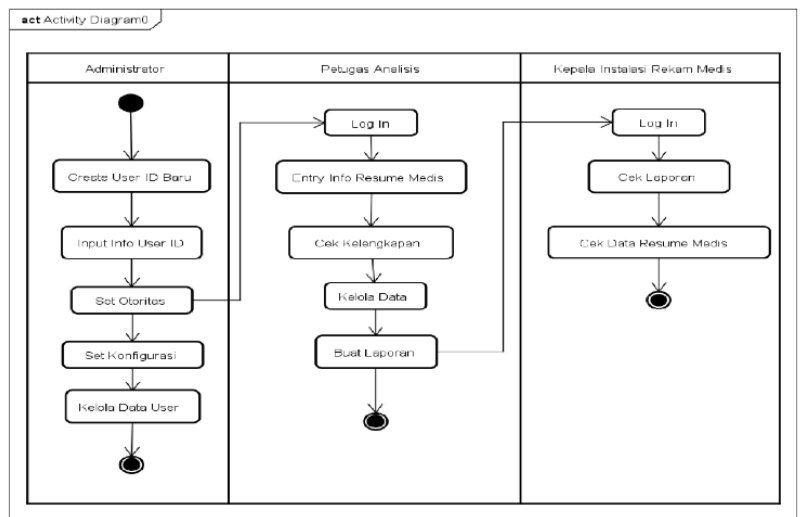

Gambar 3. Activity Diagram

\section{d. State Chart Diagram}

State chart diagram disajikan pada gambar 4.

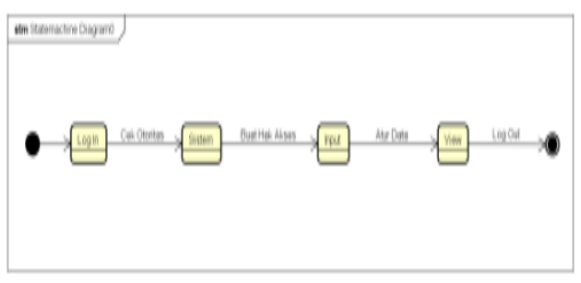

Gambar 4. State Chart Diagram

e. Sequence Diagram

Sequence diagram disajikan pada gambar 5.

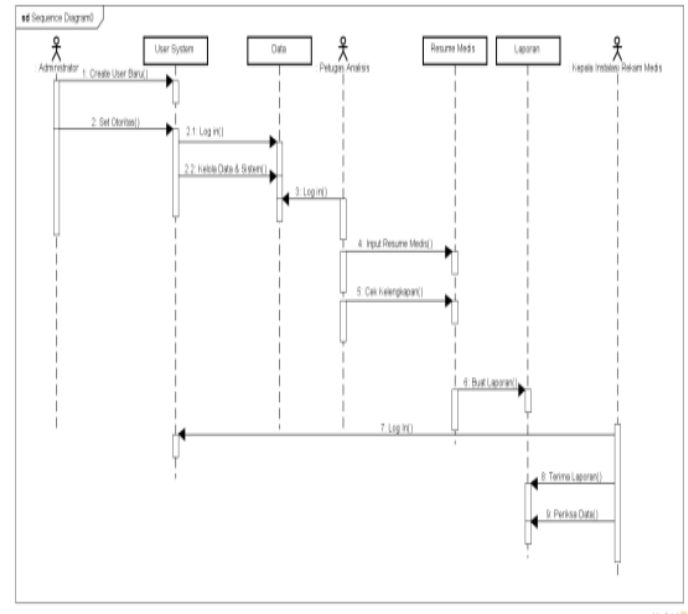

Gambar 5. Sequence Diagram

f. Collaboration Diagram

Collaboration diagram disajikan pada gambar 6.

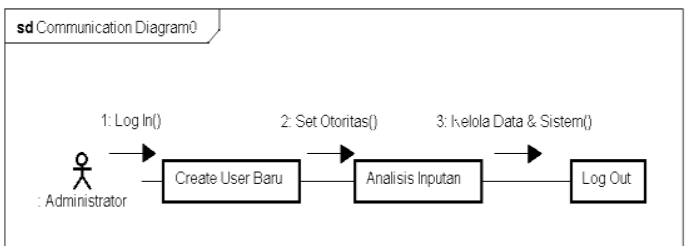

Gambar 6. Collaboration Diagram 


\section{g. Component Diagram}

Component diagram disajikan pada gambar 7.

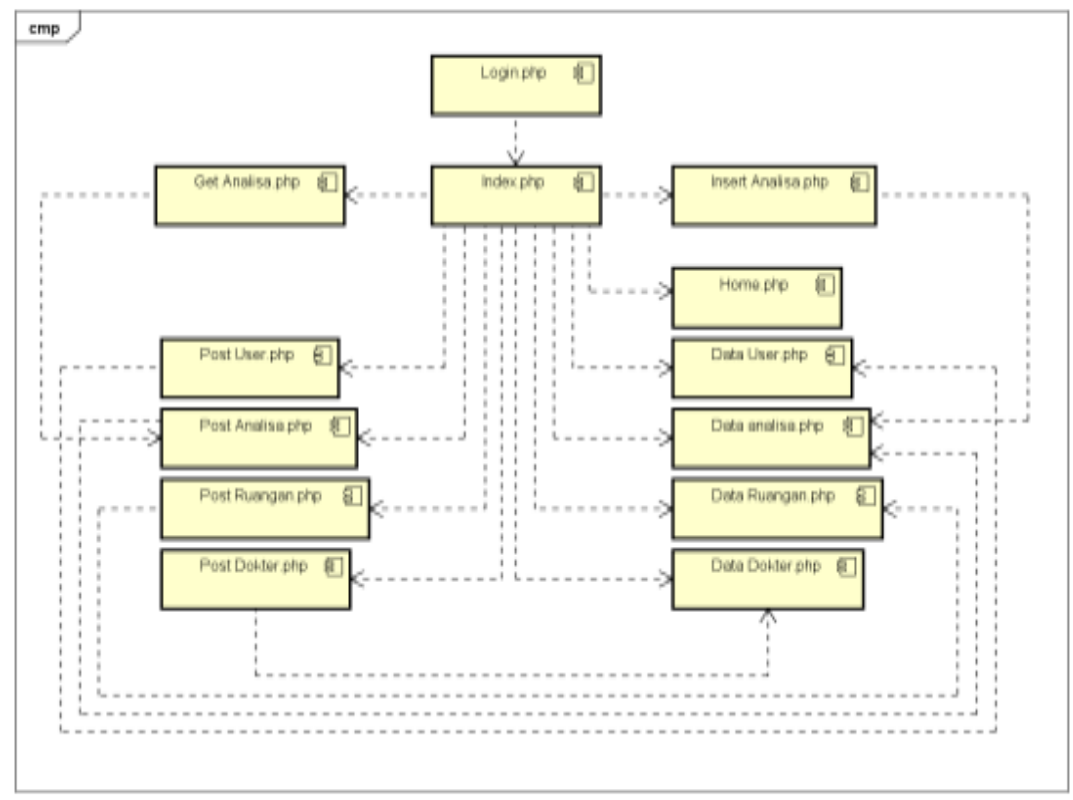

Gambar 7. Component Diagram

h. Deployment Diagram

Deployment diagram disajikan pada gambar 8.

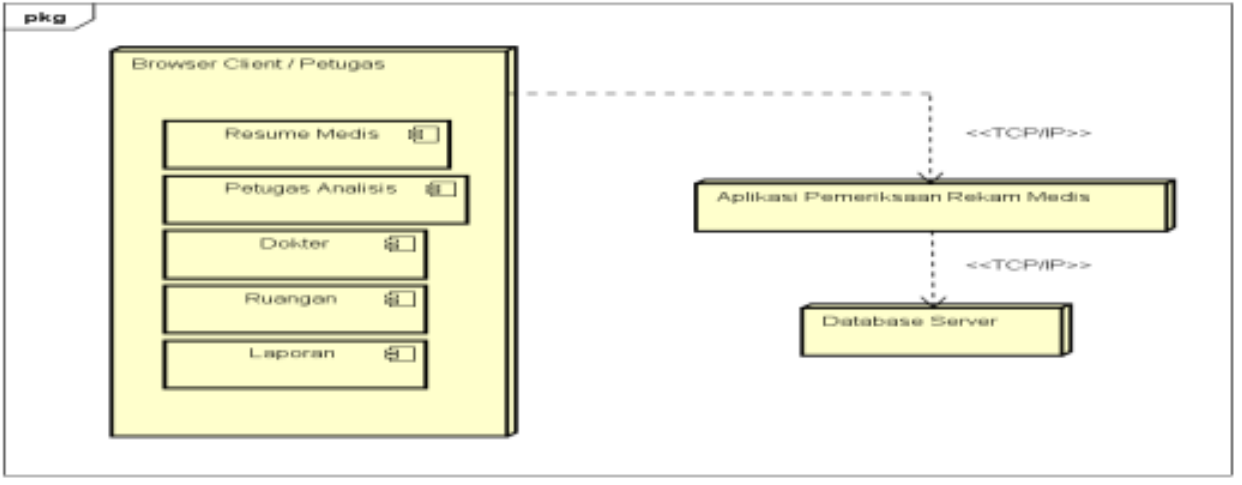

Gambar 8. Deployment Diagram

\section{i. Rancangan Basis Data}

Rancangan basis data ini dimaksudkan untuk menentukan batasan type dan inputan yang berisikan kebutuhan - kebutuhan user secara khusus pada sistem informasi yang digunakan sesuai dengan konfigurasi yang dilakukan.

\section{j. Rancangan Keluaran}

Rancangan keluaran berisi gambaran tentang Display atau output dari sistem informasi yang dirancang, informasi yang ditampilkan dapat berupa tabel informasi, data statistik, chart yang dikemas atau disajikan dalam bentuk laporan dengan beberapa parameter selection sesuai dengan kebutuhan user, data data tersebut disajikan sebagai bahan evaluasi dan pengambilan keputusan, berikut merupakan rancangan keluaran (Output) dari Sistem Informasi Kelengkapan Resume Medis.

k. Rancangan Masukan

Perancangan masukan merupakan bentuk rancangan form isian/inputan yang akan diimplementasikan pada Sistem Informasi Pemeriksaan Resume Medis. 


\section{Rancangan Dialog Layar}

Rancangan dialog layar disajikan pada gambar 9.

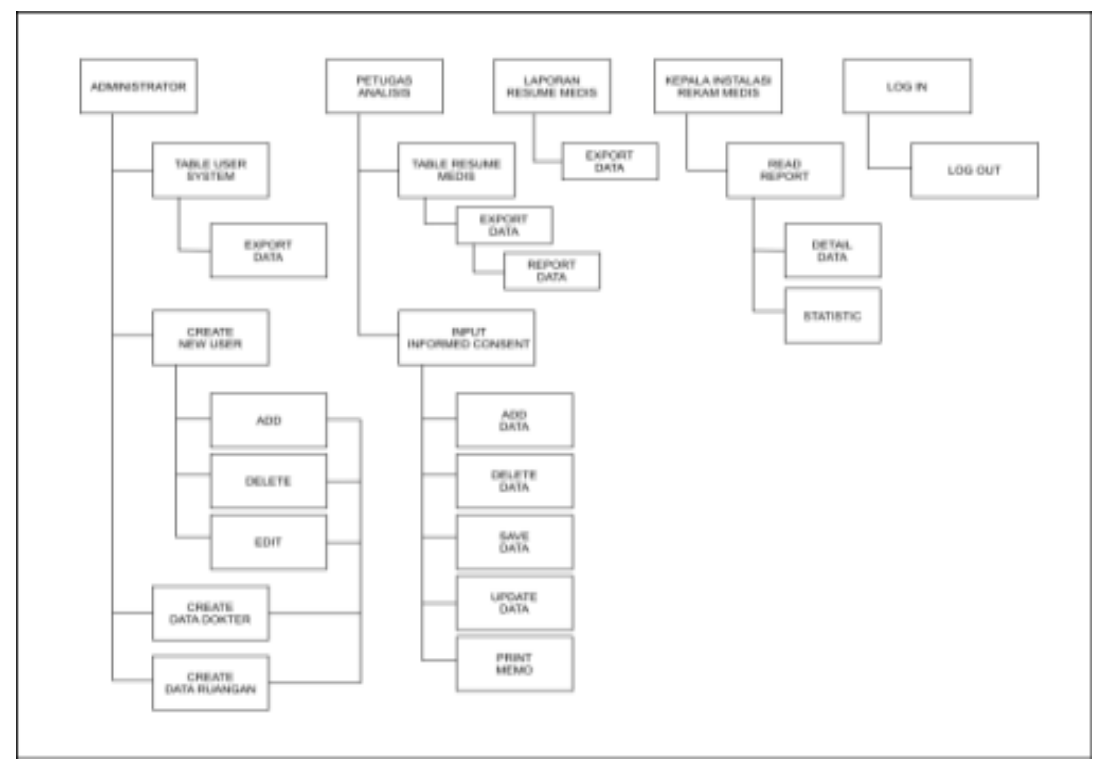

Gambar 9. Dialog Layar

m. Spesifikasi Hardware dan Software

Spesifikasi hardware dan software ini dirancang dan direkomendasikan guna mendukung hardware minimum agar sistem informasi dapat berjalan dengan baik.

n. Implementasi Sistem

1) Tampilan Form Login

Tampilan form login disajikan pada gambar 10.

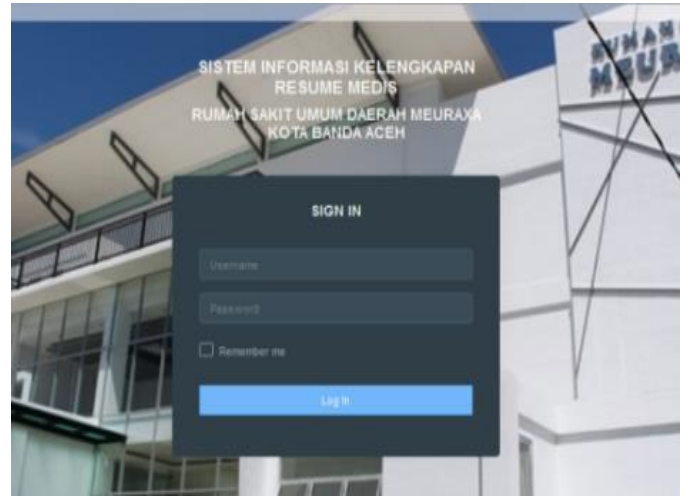

Gambar 10. Form Login

2) Tampilan Form Input User

Tampilan form input user disajikan pada gambar 11 .

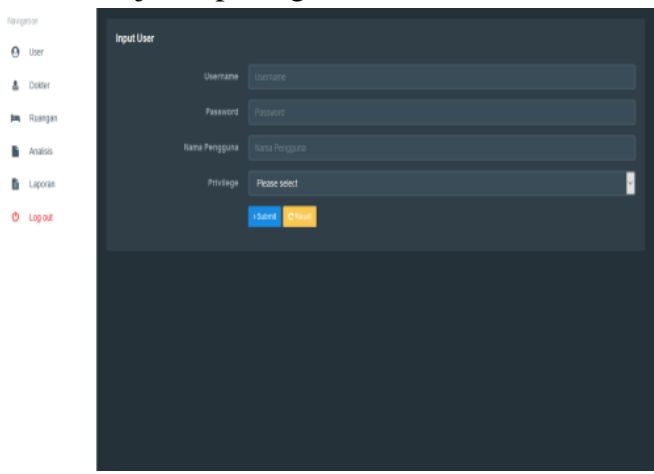

Gambar 11. Form Input User 
3) Tampilan Form Input Dokter

Tampilan form input dokter disajikan pada gambar 12.

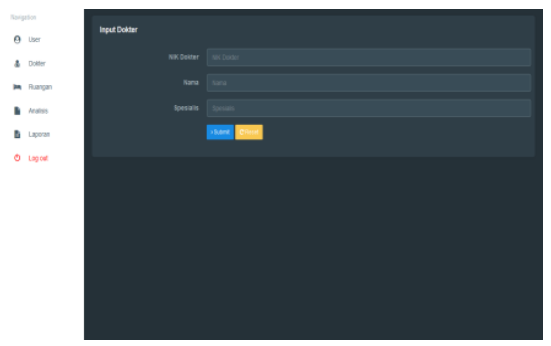

Gambar 12. Form Input Dokter

4) Tampilan Form Input Ruangan

Tampilan form input ruangan disajikan pada gambar 13.

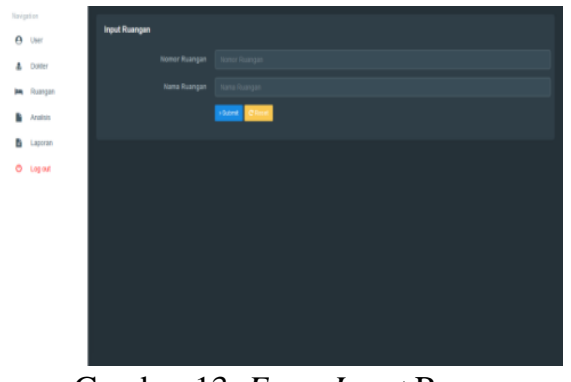

Gambar 13. Form Input Ruangan

5) Tampilan Form Input Analisis (Segmen 1)

Tampilan form input analisis (segmen 1) disajikan pada gambar 14.

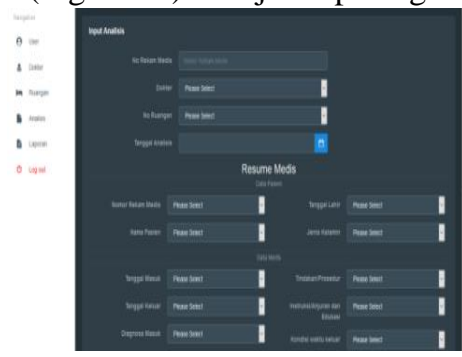

Gambar 14. Form Input Analisis

6) Tampilan Form Input Analisis (Segmen 2)

Tampilan form input analisis (segmen 2) disajikan pada gambar 15.
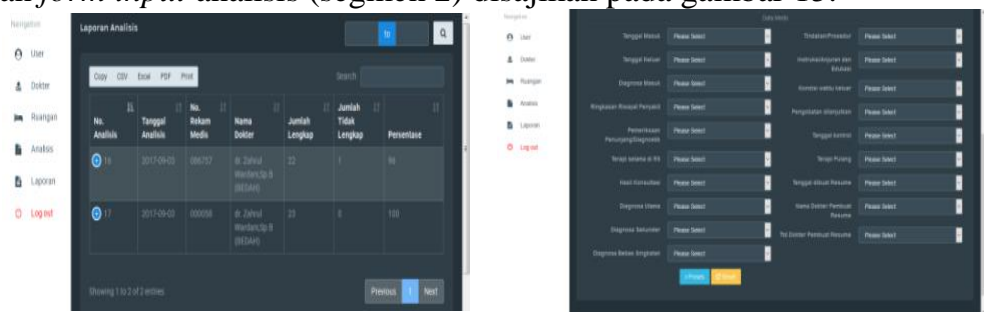

Gambar 15. Form Input Analisis

7) Tampilan Form Proses Analisis

Tampilan form proses analisis disajikan pada gambar 16.

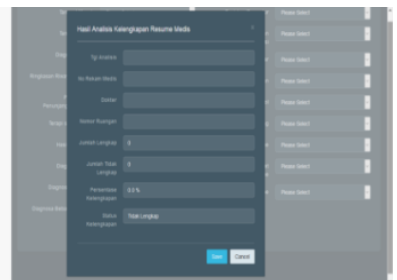

Gambar 16. Form Proses Analisis 
8) Tampilan Form Data Analisis

Tampilan form data analisis disajikan pada gambar 17.

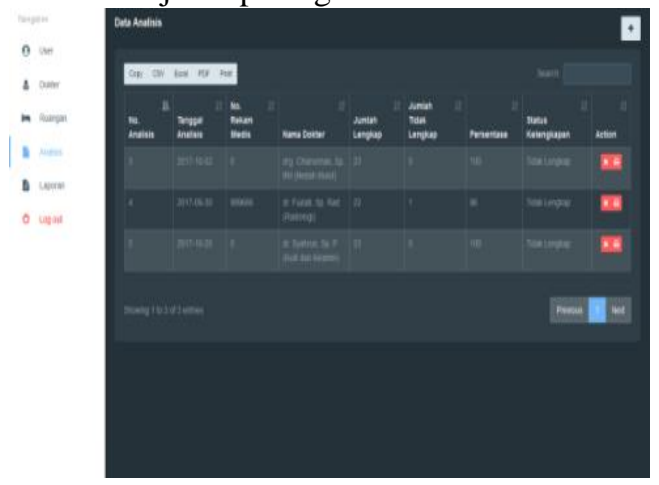

Gambar 17. Form Data Analisis

9) Tampilan Form Data Laporan

Tampilan form data analisis disajikan pada gambar 18.

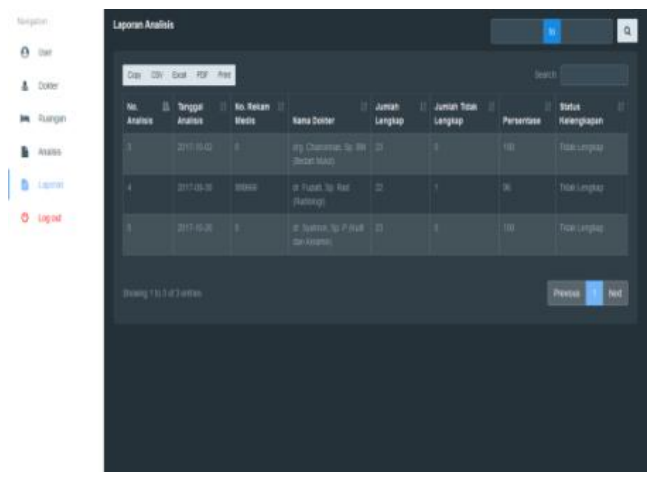

Gambar 18. Form Data Laporan

10) Tampilan Data Laporan Perhari

Tampilan data laporan perhari disajikan pada gambar 19.

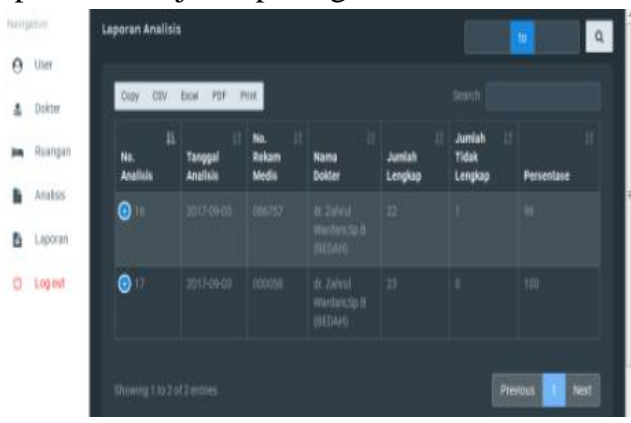

Gambar 19. Form Data Laporan Perhari

11) Tampilan Data Laporan Perbulan

Tampilan data laporan perbulan disajikan pada gambar 20.

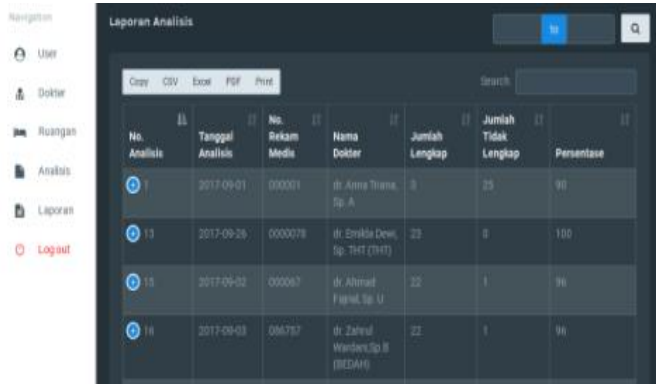

Gambar 20. Form Data Laporan Perbulan 
12) Tampilan Data Laporan Pertahun

Tampilan data laporan pertahun disajikan pada gambar 21.

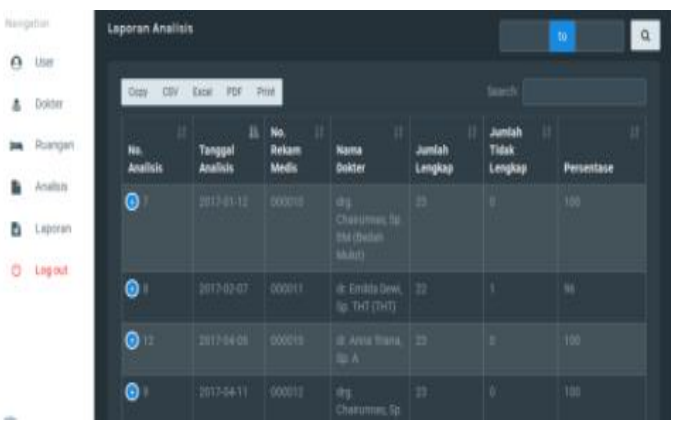

Gambar 21. Form Data Laporan Pertahun

13) Tampilan Memo Ketidaklengkapan

Tampilan memo ketidaklengkapan disajikan pada gambar 22.

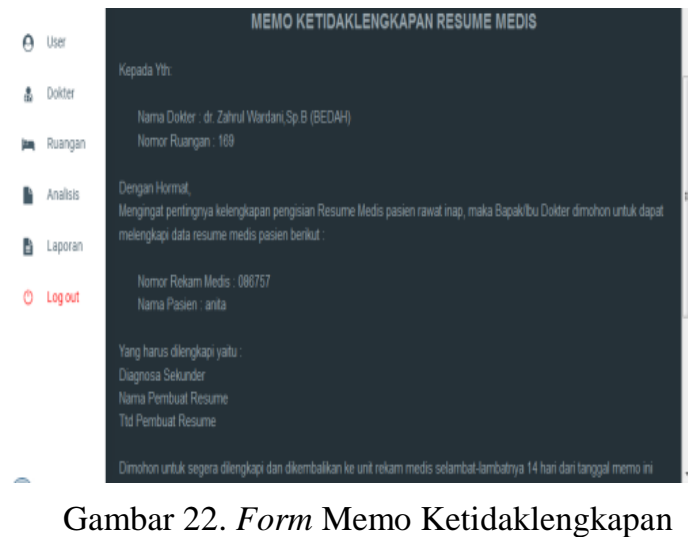

\section{KESIMPULAN}

\subsection{Kesimpulan}

Setelah melakukan Observasi tentang Perancangan Sistem Informasi Kelengkapan Pengisian Formulir Resume Medis Pasien Rawat Inap Di RSUD Meuraxa Kota Banda Aceh, penulis mengambil beberapa kesimpulan sebagai berikut:

a. Sistem Informasi Kelengkapan Resume Medis Pasien Rawat Inap Di RSUD Meuraxa Kota Banda Aceh masih belum berjalan dengan baik sehingga proses kelengkapan resume medis menjadi kurang efektif.

b. Permasalahan yang terjadi di bagian pemeriksaan kelengkapan resume medis yaitu masih adanya resume medis pasien rawat inap yang belum lengkap, sehingga rekam medis banyak dikembalikan ke ruangan untuk dilengkapi, masih sering terjadi keterlambatan pengembalian rekam medis pasien rawat inap

c. Upaya yang dilakukan untuk mengatasi permasalahan yang terjadi adalah membuat pengembangan sistem informasi yang berguna untuk memudahkan proses mengecek kelengkapan resume medis menggunakan PHP sebagai aplikasi program dan MySQL sebagai databasenya.

\subsection{Saran}

Dari kesimpulan yang telah dipaparkan, maka penulis memberikan beberapa saran dengan harapan dapat bermanfaat dan dapat menjadi bahan pertimbangan dalam meningkatkan kinerja dan kualitas dari kegiatan analisa kelengkapan pengisian formulir resume medis pasien rawat inap di RSUD Meuraxa Kota Banda Aceh. Adapun saran-saran tersebut antara lain sebagai berikut:

a. Perlu adanya penerapan sistem yang lebih baik dari sistem yang berjalan saat ini yaitu dengan merancang sistem informasi kelengkapan pengisian formulir resume medis dengan menggunakan PHP dan MySQL agar lebih efektif. 
b. Untuk mengatasi permasalahan yang terjadi yaitu:

1) Perlu adanyasosialisasi keseluruh petugas tentang keharusan pengisian resume medis. Perlu mengingatkan kepada petugas ruangan untuk selalu tepat waktu dalam mengembalikan rekam medis.

2) Perlu mengingatkan kepada petugas ruangan untuk selalu tepat waktu dalam mengembalikan rekam medis.

d. Membuat perancangan sistem informasi yang lebih terintegrasi untuk mengatasi permasalahan yang terjadi dan dapat memudahkan dalam pengolahan data yaitu membuat perancangan sistem informasi kelengkapan resume medis pasien rawat inap dengan menggunakan PHP dan MySQL di RSUD meuraxa Kota Banda Aceh.

\section{REFERENSI}

1. Akasah.2009. Modul Pengolahan Sistem Rekam Medis I, Bandung: Piksi Ganesha.

2. Departemen Kesehatan RI, Direktorat Jendral Pelayanan Medis. (1997). Pengelolaan Rekam Medis Rumah Sakit di Indonesia, Jakarta.

3. Dirjen Yanmed. (1997). Pedoman Pengelolaan Rekam Medis Rumah Sakit di Indonesia,DepKes RI, Jakarta.

4. Hanif, Al-fattah. (2009). Analisis Perancangan Sistem Informasi, Yogyakarta: Andi.

5. Hatta, Gemala R. (2010).Pedoman manajemen Informasi Kesehatan Di Sarana Pelayanan Kesehatan, UI-PRESS: Jakarta: UI-PRESS.

6. Jogiyanto, (2010).Analisis dan Desain Sistem Informasi, Yogyakarta: Krismiaji.

7. Kusumadewi, Sr. (2009). Informatika Kesehatan, Yogyakarta: Graha Ilmu.

8. Ladjamudin, Al-Bahra. (2005). Analisis dan Desain Sistem Informasi, Yogyakarta: Graha Ilmu.

9. M Shalahudin A.S Rossa. (2013).Rekayasa Perangkat Lunak, Informatika: Bandung: Informatika.

10. Nazir. (1998). Metode Penelitian, Jakarta: Rineka Cipta

11. Sugiyono, (2008).Metode Penelitian Kuantitatif Kualitatif dan R\&D, Bandung: Alfabeta.

12. Susanto, Azhar. (2000). Sistem Informasi Manajemen Konsep dan Pengembangannya, Bandung: Linggajaya. 